IdeAs

Idées d'Amériques

$7 \mid 2016$

Cinéma et histoire dans les Amériques

\title{
Perrault e a narrativa de travessias
}

Perrault et le récit de parcours

Perrault and the narrative of journeys

Perrault y la narrativa de travesías

\section{Henri Arraes Gervaiseau}

\section{OpenEdition}

\section{Journals}

Electronic version

URL: https://journals.openedition.org/ideas/1462

DOI: 10.4000/ideas.1462

ISSN: 1950-5701

\section{Publisher}

Institut des Amériques

\section{Electronic reference}

Henri Arraes Gervaiseau, "Perrault e a narrativa de travessias", IdeAs [Online], 7 | 2016, Online since 28 June 2016, connection on 20 October 2022. URL: http://journals.openedition.org/ideas/1462 ; DOI: https://doi.org/10.4000/ideas.1462

This text was automatically generated on 20 October 2022

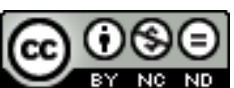

Creative Commons - Attribution-NonCommercial-NoDerivatives 4.0 International - CC BY-NC-ND 4.0 https://creativecommons.org/licenses/by-nc-nd/4.0/ 


\title{
Perrault e a narrativa de travessias
}

\author{
Perrault et le récit de parcours \\ Perrault and the narrative of journeys \\ Perrault y la narrativa de travesías
}

Henri Arraes Gervaiseau

O presente artigo é fruto parcial de pesquisa apoiada pela FAPESP, a quem agradeço pelo apoio recebido.

\section{Introdução}

1 O deslocamento de pessoas, dentro do território de um país, e de um país para o outro, e as suas implicações humanas e sociais, são questões centrais da história contemporânea, desde pelo menos meados do século XIX. Estes fenômenos têm sido objeto de estudos recorrentes no campo das ciências humanas e sociais. Também constituiram, muito cedo, um foco de interesse para os cineastas.

2 Para além da produção dos filmes de viagem do entre guerras que tão acertadamente Bazin apontou como remetendo a uma etnografia do explorador ${ }^{1}$, é a partir do advento do cinema moderno (que surge dos escombros da Segunda Guerra), que se delineiam novos caminhos para a produção que historicamente foi sendo denominada de documentária, e se configuram novas abordagens, de cunho mais ensaístico, no que concerne filmes envolvendo deslocamentos espaciais.

3 No contexto do processo de descolonização que se sedimenta a partir daquele período histórico, parece se tornar mais claro para alguns realizadores mais inquietos que a travessia de espaços sociais e geográficos distantes de suas vivencias habituais é potencialmente capaz de estimular, nos personagens, o exercício da comparação entre modos de vida e de estar no mundo.

4 Nas abordagens mais instigantes que se delineiam no campo do documentário, a partir da segunda metade do século XX, se configura uma maior compreensão daquilo que poderíamos denominar a dimensão antropológica do deslocamento espacial. 
5 Efetivamente, como nos lembra de Certeau, que retoma considerações de MerleauPonty sobre a dimensão antropológica do espaço, a experiência existencial do espaço exprime uma estrutura essencial do ser humano, como ser situado em relação com um meio - um ser situado por um desejo, indissociável de uma direção de existência, e plantado no espaço de uma paisagem (Certeau M. de, 2004 : 202).

6 A organização de viagens com os personagens, na abordagem cinematográfica do cineasta quebequense Pierre Perrault, é um frutífero modo de estimular, no espírito dos mesmos, comparações entre um antes e um depois e de favorecer a emergência de narrativas a respeito das passagens entre este antes e este depois. Além disso, a travessia de espaços sociais e geográficos distantes de suas vivências cotidianas, estimula o exercício da comparação entre modos de vida e de estar no mundo, e toca, diretamente, no caso dos personagens de Perrault, na questão central do pertencimento ${ }^{2}$.

7 Experiências de alteridade são colocadas em jogo, na travessia do percurso, suscetíveis de transformar o individuo que se desloca, e de constituí-lo, como outro, na sua relação consigo próprio e com outrem.

8 É o que acontece em filmes de Perrault tais como Le règne du jour (1967), Un pays sans bon sens (1970), C'était un québecois en Bretagne, madame (1977), Les voiles en bas et en travers (1983), La grande allure (1984).

9 Menos celebrado do que Pour la suite du monde (1962), Le règne du jour, entretanto, é um dos filmes mais originais do grande realizador quebequense. É por isso que o escolhi para abordar as questões sintetizadas acima.

10 Num primeiro momento, evocarei, de modo sucinto, uma das estratégias de filmagem envolvidas, para, em seguida, centrar-me na construção da narrativa e nos procedimentos de montagem.

\section{Colocar em situação, uma estratégia de filmagem}

11 Uma das mais inovadoras estratégias de filmagem adotadas por Perrault foi a colocação em situação dos personagens, a partir, evidentemente, do estabelecimento prévio de uma relação de confiança entre o cineasta e as pessoas que desejava filmar. Não se tratava, como no caso do velho sonho do cineasta soviético Dziga Vertov, de surpreender e registrar o movimento aleatório de indivíduos em diversas situações do dia a dia. Ainda menos, como no caso do cineasta americano Robert Flaherty, de uma atenta re-encenação de gestos e de situações que remeteriam a modos de vida que não mais existiam, com vistas a dar a impressão, para o espectador, que esses gestos e essas situações haviam ocorrido espontaneamente, de modo casual, frente à câmera ${ }^{3}$.

12 A estratégia de abordagem central de Perrault é a de colocar as pessoas a serem filmadas em situação. Como apontou Marsolais, nos filmes do diretor quebequense, as pessoas vivem situações que a câmera capta no próprio momento do seu surgimento (Marsolais G., 2007). Trata-se, com a cumplicidade dos envolvidos, de colocá-los no coração de uma ação que libera uma palavra intensamente vivida, palavra que emerge, na maior parte das vezes, em situações de diálogos. Como Michel Marie sublinhou, os personagens são filmados « em situação de palavras, em fragmentos de suas vivências » (Marie M., 1984 : 50). Eis porque Perrault denominava a sua abordagem cinematográfica de cinema do vivido. 
13 Neste quadro, é marcante como já apontava Alburni, a propósito de Le règne du jour, «o extremo respeito com o qual os seres são filmados »(Alburni R., 1969: 60), notadamente, em cenas tão difíceis como as de uma intimidade conjugal num casal de idosos.

14 Deve ser destacado, no que tange este filme, a opção por inventar uma viagem a França envolvendo vários personagens de uma mesma família, não apenas o ancião Alexis, mas ainda Marie, a sua esposa, Leopold, seu filho, e Marie-Paule, a sua nora. Esta opção irá permitir que o referido grupo compartilhe experiências no curso da viagem e ulteriormente, de expor para o espectador como uma mesma experiência é percebida de modo diferencial por aqueles que a viveram. Na medida em que os relatos das vivências, pelos protagonistas, ocorrem com uma gama bastante variada de interlocutores, a diferença dessas percepções torna-se mais aparente.

15 Ao convidar o pequeno grupo familiar a atravessar o oceano para conhecer a terra do seus ancestrais, Perrault atendia, em primeiro lugar, a um antigo sonho de Alexis. Para o ancião, a viagem constituía a oportunidade única de uma busca da genealogia de sua família e da descoberta de rastros das viagens, no século XVI, do navegador Jacques Cartier, primeiro francês a explorar e escrever sobre o território que veio posteriormente a ser chamado de Canadá. Como mostra bem, também, o filme anterior de Perrault, Pour la suite du monde (1962), Alexis tinha verdadeira veneração pela figura mítica do grande explorador.

\section{Construção da narrativa e procedimentos de montagem}

Um dos aspectos mais inovadores do filme é o da colocação em relação, através da montagem, de complexos feixes de relações temporais entre as situações mostradas no filme. Há um jogo recorrente na ordenação da sucessão das cenas que constituem o relato para o espectador, das etapas do percurso.

Irei usar os termos antes, durante e depois para designar cenas que ocorrem antes, durante e depois da viagem. Após o segmento de abertura, que dura aproximadamente dez minutos, se sucedem, até o final do filme, uma série de sequências, diferenciadas por títulos que aparecem na tela, seja com letras brancas sobre fundo preto, seja em sobreimpressão sobre alguma imagem inicial da sequência. Há um vai e vem recorrente no tempo, no curso do desenrolar do filme, no interior das sequências, entre estes tempos. A predominância de um ou de outro se altera no decorrer da narrativa.

É grande a complexidade das configurações temporais compostas pela montagem. Cenas que ocorrem no durante e no depois da viagem podem estar centradas na narrativa de um antes muito anterior à viagem da família, tais como a prisão, a deportação para Buchenwald e a volta para casa de Martin, garde-chasse.

19 O antes se configura, de início, na primeira parte da sequência de abertura do filme. Assistimos então ao convite à viagem, feito por um padre e à aceitação do mesmo pela família, que desde sempre residia na Isle-aux-Coudres, situada no meio do rio SaintLaurent, um dos maiores rios do mundo. o padre é um parente não muito próximo do casal, autor de um estudo sobre os moradores do Canadá com nome de Tremblay, sobrenome mais usual no país e nome de família do casal. A segunda parte da abertura, 
de transição, mostra a passagem por Nova Iorque em que a família reencontra em um aquário, um marsuíno ${ }^{4}$.

Mesmo neste antes da viagem, já há uma configuração singular: a primeira cena, em que assistimos a uma conversa entre o padre e o casal composto por Alexis e Marie, aconteceu na realidade após a terceira, em que o padre chega na casa do casal, ausente, $\mathrm{e}$ pergunta para a pessoa que o atende, na porta de entrada, se é ali que mora o Alexis.

Na primeira cena da conversa de Alexis com o padre, Alexis lhe diz que Marie e ele tiveram muitos filhos: " criamos 16 filhos; temos o primeiro que é Leopold. Temos setenta e dois netos e sete bisnetos. Isto povoou o Canadá ». Um pouco mais adiante, Leopold matiza « é preciso mais dos que Tremblay para constituir um povo ».

Apesar da ponderação do Leopold, é notável a dimensão épica que o relato adquire desde a primeira fala de Alexis, com a sua sugestão bem humorada de que foram os Tremblay que povoaram o Canadá. Para Alexis, através da saga dos Tremblay, é a história do povoamento do seu país que se desenha.

23 Cabe ressaltar uma dimensão épica de outra natureza, de cunho mais brechtiano, neste filme de Perrault, que não se contenta, como já mencionado, em expor os acontecimentos da viagem tomados na cronologia do seu desenvolvimento (DidiHuberman G., 2009).

24 À semelhança de Brecht, na arquitetura de composição do seu filme, Perrault prende-se menos aos episódios da estória do que à « rede de relações que se esconde, por detrás dos acontecimentos, já que há sempre uma outra realidade por detrás da que se $\operatorname{descreve}^{5}$ ». Por isso introduz rupturas e interrupções no relato das múltiplas ocorrências e situações de diálogos da viagem. Trata-se de interromper a aparente fluidez do desenrolar, produzir descontinuidades narrativas, de tal sorte que as situações se critiquem dialeticamente umas as outras, se entrechoquem, para melhor apontar diferenças, e suscitar confrontos e comparações.

Uma grande liberdade norteia também o processo de composição das inter-relações entre as falas dos personagens e as imagens que as acompanham. Por vezes, o narrador encontra-se na França, mas o espectador vê imagens da Isle-aux-Coudres, ou o narrador já se encontra de volta na ilha, e vemos imagens da França (Marsolais G., 2007 : 19).

\section{Desenvolvimento da narrativa}

Entre as já citadas cenas de Marie e Alexis conversando com o padre e da chegada deste último na casa do casal de anciões, encontram-se outras duas, em que ouvimos uma canção. Aparecem então os créditos iniciais do filme.

Enquanto ouvimos a canção, vemos alguém andando numa estrada empoeirada e, em seguida, de longe, três pessoas no meio de um campo florido, que saberemos, em seguida, serem Alexis, Marie e o seu filho Leopold.

Na letra da canção, o sujeito da enunciação se dirige exclusivamente a Marie, a quem solicita reiteradamente (dis-moi Marie) que responda às suas dúvidas existenciais. E que neste início de filme e da canção, o tema da travessia (bout de chemin), do sofrimento que ela envolve (bout de misère), e do envelhecimento (est-ce parce qu'on vieillit) são postos em destaque, bem como o da reminiscência (et le temps de temps d'enfances [...] me 
revient comme un présent) e da inevitável finitude da vida (Parce que c'est de vivre pourtant qu'on meurt).

Na segunda metade da abertura, Alexis dialoga com o proprietário americano do aquário de Nova Iorque, e lhe dá a notícia da sua iminente viagem ao berço dos seus ancestrais. $O$ americano não entende de início o significado da palavra berço, em francês, o que permite uma acentuação do significado desta viagem, por Alexis, e a evocação da figura de Pierre Tremblay, ancestral mítico da família, que emigrou do antigo condado francês do Perche para o Canadá no século XVII.

Na sequência seguinte, La v'lá ta France, bem como na próxima, predomina o durante. Nas cenas no convés do navio que os leva para a França, destaca-se o da aproximação do porto do Havre. Ouvimos então a voz off de Leopold gritando para o seu pai Alexis a frase que dá título à sequência: "Aqui está a sua França ». Quando tal frase é dita, o porto encontra-se submergido na bruma, e de fato ninguém vê grande coisa. Através da montagem, abre-se um primeiro elemento de incerteza sobre o tipo de reconhecimento que a viagem irá permitir.

31 A sequência seguinte, Percherons du 20ème siécle, centra-se em diálogos ocorridos em duas aldeias do Perche.

O primeiro acontece na residência de Madame Montagne, autora de um estudo sobre a história da emigração percheronne, que hospedou os Tremblay. Este diálogo é comentado, através da inserção, no meio da sequência, de um outro diálogo, ocorrido no depois, entre Alexis e o amigo Grand Louis, interlocutor central para Leopold e Alexis.

Ao contar para o seu amigo, que tinha permanecido na Isle-aux-Coudres, a sua visita a casa da Madame Montagne, Alexis salienta a sua dificuldade de entender os discursos da referida senhora, discursos que ele qualifica como sendo " um pouco distantes uns dos outros ». É de se notar que este trecho de conversa entre os dois amigos parece ter sido extraído da cena que serviu de base para composição de uma sequência que aparece na última parte do filme, justamente intitulada Reflexões sobre a linguagem.

Perrault, através da fragmentação dos registros desta cena, desta montagem a distância, para retomar o termo consagrado pelo grande cineasta armênio Pelechian, procede, ironicamente, de modo semelhante a Madame Montagne, mantendo os seus discursos " um pouco distantes uns dos outros ", o que não facilita a compreensão do espectador.

Ao estranhamento suscitado pelo diálogo dos Tremblay com Madame Montagne, sucede, no mesmo local, a descoberta da diferença de condição, de Monsieur Clément, meeiro e morador de área rural do Perche, frente aos visitantes, agricultores e pequenos proprietários, como a maioria dos seus conterrâneos da Isle-aux-Coudres.

Na sequência subsequente, $L a$ fête du cochon, a dimensão comparativa dos modos de produção da subsistência se amplia, já que agora também envolve usos e costumes a eles relacionados. O segmento é marcado por um intenso vai e vem entre cenas envolvendo a experiência de Leopold com a carneação de um porco, durante a estadia da família junto a agricultores no Perche, e os comentários que surgem, depois da viagem, durante um ato similar de carnear, nos diálogos do mesmo Leopold com seus amigos da Isle-aux-Coudres, que nunca foram a França.

37 No final da sequência, por ocasião da descrição, por um agricultor francês, do aproveitamento de todas as partes do porco, mesmo as menos nobres, ocorre um diálogo em que se caracteriza pela primeira vez no filme, o conservadorismo de Alexis, 
e a sua oposição aos tempos modernos, que constituiriam um reino da gaspille (da gastança).

A maioria das cenas da sequência seguinte, intitulada Alexis relève la trace de ses ancêtres ocorrem no durante, em diversas localidades do Perche, e envolvem episódios da busca de Alexis pelos rastros do ancestral mítico da família, Pierre Tremblay. Um dos momentos de maior emoção da sequência, é para ele, o da visita da fazenda onde Pierre Tremblay teria nascido. Nesta ocasião beija apaixonadamente Marie após esta responder a uma indagação sua a respeito do seu contentamento de estar ali, e confessar seu menor interesse pelo assunto, mas afirmar o seu contentamento de ver o seu marido contente.

Na sequência seguinte, Les filles de La Rochelle et la mode de Paris, que se inicia mais ou menos na metade do filme, há quase predominância de cenas que ocorrem no depois frente às do durante. Alternam-se cenas de um diálogo ocorrido entre Alexis e o seu filho Leopold, ao observar o movimento de barcos e pessoas no porto de La Rochelle, com comentários e diálogos, após a viagem, de Marie, Alexis, e Leopold. Frente à observação de modos antigos de remar (la godille) em La Rochelle, Leopold sublinha que pescadores franceses ainda preservam muito mais costumes do tempo antigo do que os da sua terra. Alexis, ao concordar com o seu filho, recorre novamente ao termo de reino, salientando que o seu acabou.

Cabe observar que a palavra reino é bastante usada, ao longo do filme por Alexis, e constitui uma espécie de noção ou categoria, que serve não apenas para delimitar um período, mas ainda designa um modo de ser predominante naquele período, caracterítisco de uma geração.

41 Logo após ter declarado, "Eu, meu reino acabou ", Alexis destaca a importância da transmissão de conhecimentos entre gerações. Dirigindo-se a Leopold, acentua: « Na sua viagem, você vai aprender um pouco, talvez, para ensinar aos seus filhos. Você não está na terra só para passear ».

Como mostra essa passagem, Perrault evoca, em Le règne du Jour, uma memória transgeracional, que remete, em última instância, ao triplo reino que caracteriza esta memória, segundo Paul Ricoeur: o reino dos predecessores, o dos contemporâneos e o dos sucessores ${ }^{6}$. No caso da família Tremblay, protagonista do filme, poderíamos dizer, em primeira instância, que Alexis e Marie constituem a figura dos predecessores; contemporâneo, neste quadro, é Leopold, filho do casal, já cinquentão no filme; e sucessores são os netos e bisnetos do casal de anciões, com quem vemos Alexis conversar em diversas passagens do filme. Para Alexis, o reino dos antepassados é o do seu grande ancestral mítico, Pierre Tremblay, e, mais longe ainda, é o do navegador Jacques Cartier. Como ficará cada vez mais claro, ao longo do filme, Alexis tem, com o reino dos antepassados, e com o seu próprio reino, uma relação passadista, impregnada de nostalgia por um mundo perdido.

Um outro tipo de relação com o passado surge na cena seguinte, em que Marie, já de volta na Isle-aux Coudres, no depois, exalta simultaneamente a beleza da França e da nossa terra, e comenta que naquele país existem muitos « antigos negócios que jamais vimos, porque somos demasiado jovens, nós outros no Canadá ».

Cabe notar aqui o uso do pronome nós. É um eu coletivo que se exprime pela voz de Marie, que como pessoa humana, como indivíduo, tem perfeita consciência de que é velha. A juventude da qual ela fala aqui é a do novo mundo, de onde ela vem. 
Pouco depois, em outra cena da mesma sequência, Leopold, em diálogo com Grand Louis, irá reafirmar essa juventude do novo mundo, em que o progresso ocorreria bem mais rápido, frente a esta França da qual a família acaba de chegar.

Cabe notar também que depois de ter aparecido sublinhando a juventude do Canadá, a qual se sente pertencer, Marie ressurge, sublinhando o conservadorismo do seu marido: « Meu marido sempre foi antigo. Isto faz com que, agora velho, é ainda mais antigo. Eu, eu não admito tudo o que ele diz. Não fico contente ».

7 O conservadorismo de Alexis, efetivamente, na sequência, fica explícito nos seus diálogos com o filho, Grand Louis, e Marie. O ancião reclama sucessivamente dos excessos de máquinas, na modernidade, das vestimentas curtas das mulheres, e dos tempos atuais, piores do que os do início de sua vida de casal.

48 Marie se opõe com firmeza a esta visão idealizada de um passado de fato cheio de privações, e a este rancor contra um presente que, embora modesto, sabe que é materialmente melhor do que ontem. Entendemos que embora seja velha, não se considera antiga, como Alexis, nem moderna, mas do seu tempo. Por isso, a anciã afirma, que é preciso « admitir o dia como ele advém ».

O termo de dia é usado tanto por Alexis quanto por Marie, mas a valorização do presente, subjacente à referida afirmação, e este modo de situar-se, intuitivamente, no tempo histórico do contemporâneo (quando Marie declara: « eu sou do meu tempo ») é característico de Marie.

O equilíbrio entre durante e depois é maior na sequência seguinte La chasse à l'épouvante, no início da segunda metade do filme ${ }^{7}$. No confronto fugaz com « descendentes de altos dignitários que não falam com todo mundo ", como diz Leopold, torna-se clara não apenas a origem territorial mas a origem social dos ancestrais da família.

Há inicialmente alternância entre, por um lado, cenas de caça numa floresta envolvendo senhores bem vestidos, um guarda-caça, que para eles trabalha, e o Leopold, puxando uma matilha de cães; e, por outro lado, cenas em que Leopold comenta o ocorrido na ocasião, de volta na Isle-aux-Coudres, para amigos. Por vezes o seu comentário, no depois, torna-se over, e integra-se a visão do desenrolar da cena do durante.

52 Na segunda parte da sequência ainda vemos cenas de caça. Agora constituem pequenas inserções dentro de planos do dialogo de Alexis e Leopold com Martin, o guarda-caça, que aponta que aqueles que outrora emigraram da região para o Canadá deviam ser operários, gente do campo, ou plebeus (" des roturiers ») - categorias que na hora Alexis designa resumidamente como pertencentes às classes baixas, terminologia usada, segundo ele, no Canadá. Por isso, talvez, sugere Martin, quando esses descendentes de nobres identificaram os Tremblay como descendentes desses emigrantes, se sentiram incomodados e não desejaram falar com eles.

É notável, contrariamente, a vontade de Martin, plebeu, ele também, de conversar com a família Tremblay. E com eles compartilhar lembranças, em particular da sua deportação para o campo de concentração de Buchenwald, do qual é um sobrevivente, contrariamente aos poucos integrantes das altas classes da região que entraram para a resistência, foram deportados e não sobreviveram, na sua maioria, em função da sua menor lida com trabalhos manuais, segundo ele.

Cabe mencionar, de passagem, algo marcante, em muitos filmes de Perrault envolvendo viagens, que é este sentimento de pertencimento dos personagens ao mundo plebeu, 
des travaillants - os verdadeiros notáveis, segundo Hauris Lalancette, personagem principal do filme Era um quebequense na Bretanha, minha senhora!

Um trecho da conversa do Leopold com seus amigos, no depois, em que salienta que as suas primeiras conversas na França foram sobre a guerra, introduz a sequência seguinte, 0 reino dos soldados, em que se evoca não apenas um passado histórico, mas um tipo de lembrança emocionada que a experiência vivida da história suscita.

O uso do termo dia, aqui, ganha outra conotação, quando no cemitério que a família foi conhecer, o grupo conversa com uma senhora de idade, que lhes conta a morte de um próximo, ao combater os alemães. E comenta : « para ele, morrer na primavera, assim, no final de tarde de um belo dia, ele não podia desejar algo melhor ».

$\mathrm{Na}$ continuidade da visita ao cemitério, Marie sublinha que os franceses do lugar onde se encontram têm "lembranças que nos não temos ", lembranças da guerra, que guardaram, para " os emocionar, mais do que nós ", reconhecendo, deste modo, uma alteridade histórica na experiência existencial dos franceses frente à experiência de vida dos quebequenses.

o final da emocionante, embora contida, subsequente retomada pelo guarda-caça Martin da narrativa do seu aprisionamento e da sua sobrevivência à tragédia da deportação - quando Alexis exalta a sua notável coragem de homem francês, coragem que, segundo ele, não se encontraria no Canadá -, desemboca na narrativa complementar da longa espera de sua volta, pela esposa. Frente ao comentário de Alexis que ela deve ter se angustiado muito, a mulher afirma com veemência o seu pertencimento à nação francesa, base de sua resistência pessoal à dor da então muito provável morte do seu marido: «Eu era francesa $100 \%$ ».

59 Já fora da casa de Martin, vemos então Alexis, profundamente impactado e pleno de admiração pela coragem deste humilde casal, confidenciar a Leopold, que "nós subentendido os canadenses -, nos não temos mais sangue francês ", sangue francês que será tema de uma das últimas sequências do filme.

60 Em, seguida, na sequência, Alexis relève la trace de Jacques Cartier, assistimos a uma discussão entre Marie e Alexis, ocorrida em Saint-Malo, porto de partida do referido explorador bretão do século XVI. A discussão ocorre em função do desejo de Alexis, que se revela rapidamente irrealizável, da construção, por um artesão local de uma réplica em miniatura da embarcação de Cartier. $O$ ancião se justifica afirmando a sua vontade de transmitir esta lembrança da viagem aos netos. Marie discorda, salientando que a nova geração não têm mais o mesmo apego à figura do explorador.

61 No contexto do diálogo, novamente, evidencia-se a inquietude de Alexis quanto à efetividade da transmissão do que considera a herança das referências históricas que constituem o seu sentimento de pertencimento enquanto canadense francês, bem como a efetividade da transmissão de algo que remete a uma dimensão mais intima, própria de cada pessoa, poeticamente designada por ele como constituindo o seu natural.

62 Assistimos, na mesma sequência, a outra discussão, ocorrida antes da viagem, frente aos pedidos de presentes dos netos. Aqui, outra diferença se explicita, entre os dois cônjuges, que envolve a menor disponibilidade financeira de Marie. Entremeando planos desta cena, são inseridos planos do depois, em que Alexis entrega presentes para os netos numa grande reunião familiar.

63 Marie preocupa-se em preservar alguma quantia para o seu enterro, pela própria consciência aguda que tem da sua velhice e da maior proximidade então da morte 
(Marie: " penso em morrer um dia »). Alexis, dispondo de maiores recursos, se prontifica, de modo um tanto machista, a atender aos pedidos dos netos. E ainda zomba da esposa, dizendo que ela não hesita em tirar dinheiro da carteira dele, afirmação frente à qual ela responde com firmeza: « Não te incomoda dizer isto frente ao mundo [...] mesmo se não é verdade? ». Entremeando planos desta cena, situada no antes, como apontado, são inseridos planos do depois, em que Alexis entrega os presentes. A sequência seguinte, Réflexions sur le langage, é a primeira, até agora, a situar-se inteiramente no depois, inaugurando, de certo modo, o movimento final do filme, onde o depois irá predominar, apesar da existência, nesse movimento final, de outros tempos. Estas reflexões, a posteriori, sobre a linguagem, iniciam-se com comentários sobre a diferença de costumes (os banheiros nos bares de Paris) e sobre os nomes diferentes dados às coisas nos dois países. Ao final da sequência, assistimos a uma bem humorada conversa entre Alexis e Grand Louis. Grand Louis primeiro enumera uma série de diferenças do falar, entre a França e o Canadá, entre a gente da cidade de Montréal e os habitantes da ilha em que se encontram. Em seguida, aponta para a diferença do falar entre duas pessoas (no caso, entre ele e Alexis), sublinhando, a seu modo, as dificuldades de comunicação que podem surgir em qualquer diálogo inter-subjetivo.

A sequência significativamente intitulada Ah que les beaux jours sont courts, é a mais lírica de todas. É também aquela onde, em função da experiência de alteridade que a viagem representou para ambos, o mistério da intimidade de Marie e das suas eventuais metamorfoses parece tornar-se mais opaco para Alexis.

67 A primeira parte da sequência ocorre no depois. Nela, basicamente, entretanto, se evoca um antes bem anterior à viagem, que é o da chegada de Marie, para se casar com Alexis. A chegada é contada do ponto de vista dela. Alexis parece escutar pela primeira vez esta narrativa. Entremeando o final do depoimento, surgem algumas fotos em que Marie aparece jovem e linda. Estes inserts também jogam com a memória do espectador, já que em uma delas, está com a mesma aparência fisionômica, de penteado e de figurino que numa foto do início do filme. Neste momento, Marie alude, radiante, ao nascimento dos seus primeiros filhos.

Segue-se uma longa cena de Marie andando na neve, enquanto ouvimos, em off, o segundo trecho da canção composta para ela por Perrault. A canção enfatiza a fugacidade do passar dos dias, a simultânea apreciação do valor da duração do instante vivido e a convocação da lembrança, no passado, do cair da neve, quando Marie, então jovem noiva, apaixonada, enfrentando muitas dificuldades na sua viagem, desembarcou na Isle-aux-Coudres, para se casar com Alexis.

69 Como sempre no final de cada trecho, volta o refrão que sublinha a inevitável finitude da vida ("Porque é de viver, entretanto, que se morre »). Como que respondendo à suplica do enunciador (« Diga-me Marie »), a primeira parte dessa sequência termina-se com a lembrança enigmática de algo que a impressionou até o ultimo grau naquele dia em que chegou. Eis então que, em uma das únicas vezes em que ouvimos a voz de Perrault no filme, surge em off a pergunta: « faz quanto tempo? ». Marie responde: « 56 anos ", tempo próximo a duração do seu casamento.

70 Na segunda parte da sequência, há um jogo maior de alternância entre o antes, o muito antes da viagem, o durante, e o depois. $\mathrm{O}$ eixo, aqui, é a discussão pelo casal do significado da viagem para Marie, e, em última instância, da capacidade de Alexis de se doar a ela. 
71 Esta segunda parte se inicia com a inserção de um novo trecho do primeiro diálogo a que assistimos no filme, entre o padre e Alexis, no qual este último salienta que a viagem para a França será a viagem de núpcias que eles nunca tiveram. Seguem-se varias cenas, no navio, em que Alexis faz todo um charme e um jogo duro, sobre a possibilidade ou não de dar um dispositivo de espelhos similar ao que Marie está alegremente desfrutando na cabine. Na última destas cenas, Alexis lembra a promessa que há 56 anos, ele tinha feito, de « se entregar totalmente a ela », como se esta doação constituísse, então, o maior presente que ele poderia oferecer-lhe. Em seguida, Marie comenta que "se lembra deste presente ». Alexis, então pergunta se este era um presente aceitável. Sorrindo, Marie responde, enigmática, para nova surpresa e inquietude do seu marido, que ela não podia revelar este segredo, um segredo só dela.

72 A alegria dela, ao se casar, no filme, parece patente. Não tanto nas fotos antigas, em que aparece jovem, linda e elegante. Mas nas palavras da nova canção que a ouvimos, então, cantar.

73 Ressalta, na letra, a ênfase, novamente, na fugacidade do passar dos dias, no caso felizes ou belos, e a alusão ao fato que uma senhorita se deixou levar, que poderia ser, no caso, a própria Marie, na época de sua juventude: «Souriante et légére. Je la soulevais de terre. Mam'zelle s'est laissée faire. Que les beaux jours sont courts ».

74 A sequência seguinte, De l'acharnation, do ponto de vista da sua configuração temporal, passa-se quase toda no depois, quando o casal descobre que sem o seu consentimento, um dos filhos mandou matar uma égua velha. Aqui, encontra-se mais uma vez trazida a questão da finitude da vida, e, pela primeira vez, a ideia de um momento crepuscular da existência.

75 Deixem viver os velhos, parece apontar na sequência, Alexis. Que eles possam dispor dos agrados da velhice (« agréments des vieux jours »). Seja o trator do Grand Louis, ou o relógio de pêndulo antigo do Alexis. A compra deste último objeto, na França, e a sua inutilidade aparente inicial, no Canadá, encontram-se no centro da sequência subsequente, Les monuments inutiles.

É marcante, nas cenas, a impaciência do Alexis, que se acha enganado, porque o relógio comprado na França, inicialmente, não parece funcionar. De modo muito evidente, o ancião tem consciência, que lhe dói, que não lhe restam muitos anos de vida (« se Deus me deixar viver pelo menos dois anos mais », exclama, então em meio a sua fúria). Chega a querer destruir o relógio, monumento inútil, com um machado, no que é impedido por Leopold e Marie.

O penúltimo segmento Le sang français, composta por um plano sequência de uma conversa entre Alexis e Grand Louis, na volta da viagem, dialoga com a sequência intitulada Le règne des soldats, na qual sangue francês já designava metaforicamente algo como uma herança histórica.

78 Em última instância aqui, estão em questão, a condição e o futuro do país ao qual pertencem. No qual, eles, canadenses com ancestrais franceses, desejam ver os seus direitos, a sua parte, reconhecida. Alexis, que considera que ainda tem sangue francês, deseja que frente aos canadenses ingleses, os canadenses franceses possam obter maior reconhecimento. O desejo que ele verbaliza, em última instância, é o de que a França venha retomar o Canadá.

79 Outra é a posição de Grand Louis. Para falar como o personagem Michel Garneau, em outro filme de Perrault, " ao dizer o dizer do alhures de onde é », Grand Louis acaba por 
apontar poeticamente, na sua fabulação, para a singularidade americana do seu povo, ao salientar que junto à diminuta porção de sangue francês que corre em suas veias, há um pouco de Pepsi, de Coca Cola e de Seven Up ${ }^{8}$.

A última sequência, La chanson de Marie, do ponto de vista da ação, relaciona-se com instalação, que, ao cabo, revela-se bem sucedida, do relógio de pêndulo em um cômodo da casa. Esta ação se desenvolve enquanto ouvimos o último trecho da Canção de Marie. Parece retornar, de modo ainda mais singelo, neste final, o leitmotiv da inquietude existencial frente à perspectiva da finitude corporal e da subsequente transmutação dos seres pela natureza (« Dis Marie [...] dis ce que tu penses de la terre qui reprendra nos visages pour en faire des feuillages »).

81 Talvez não seja por acaso que as últimas palavras da canção sejam: « Mas nada mais nos acontecerá do que a vida que vivimos. Para que o tempo passe ». Esta presença do tempo que passa é muito concretamente marcada pela feliz expressão de Marie na última imagem do filme, ao constatar que o relógio finalmente está funcionando (« Elle marche ", subentendido, l'horloge).

\section{Considerações finais}

Se, no decorrer do percurso que a narrativa constitui, o espectador se defronta, de modo recorrente, com os mais variados exercícios de comparação, pelos personagens, entre costumes e modos de vidas de regiões da França e da Isle-aux-Coudres, ressalta entretanto, no final da travessia e do filme, o sentimento, ao cabo, reforçado, de pertencimento a um território do novo mundo que possui uma singularidade histórica frente à experiência nacional francesa. Sentimento compartilhado, no caso, principalmente por Marie e o seu filho Leopold, e expresso com grande força poética por Grand Louis, que não efetuou a viagem, mas soube captar os seus ecos nas falas dos seus amigos viajantes.

83 Ao término da travessia, contrariamente, Alexis parece ainda mais preso a uma idealização do passado. 0 seu sentimento mais forte de pertencimento relaciona-se ao reino dos antepassados, e ao velho mundo que, de certo modo, a França representa para Marie e Leopold. Além disso, como vimos, Alexis sai da experiência da viagem emocionalmente desestabilizado frente à repentina descoberta, aos oitenta anos, de insuspeitadas diferenças de percepção, entre ele e a sua esposa, sobre a experiência de vida em comum e sobre a própria experiência humana de passagem do tempo.

84 A última cena do filme, em que vemos Marie sorrir, frente ao relógio pontuando a passagem do tempo, mostrando o tempo presente passando, aponta para a continuidade da vida, e para o fato de que tanto Alexis quanto Marie ainda estão juntos, imersos no reino do dia.

A sabedoria de admitir " o dia como ele advém ", e esta abertura ao imponderável da vida, a sua vivacidade, é entretanto, neste filme, como mostramos, próprio da Marie. Ao defrontar-se, junto com Alexis, com situações e pessoas estranhas ao seu contexto de vida habitual, Marie situa-se de modo diferente do seu marido.

$\mathrm{Na}$ volta da viagem, o ineditismo da experiência favorece o confronto de pontos de vistas do casal, e uma revisão da história em comum, de onde surge progressivamente, para Alexis e para o espectador, uma outra Marie, que parece então ter se apropriado 
mais plenamente de sua própria história enquanto mulher, esposa, mãe e habitante do novo mundo.

Le règne du jour antecede o momento de maior politização da questão do pertencimento na filmografia de Pierre Perrault, que se sedimenta, como apontou Desjardins, a partir da filmagem do seu filme seguinte, Les voitures d'eau (1968). E se fortalece, sobretudo, no curso do processo de realização dos dois filmes subsequentes, Un pays sans bon sens (1970) e L'Acadie, l'Acadie ?! (1971).

88 Entretanto, para além da heterogeneidade das experiências existenciais vivenciadas, das modificações operadas nos modos de sentir e estar no mundo dos personagens envolvidos na travessia, 0 reino do dia, através da enigmática composição de sua narrativa, contribuiu - assim como Para a continuação do mundo, mas de modo bem diferente - para a constituição de um lugar de memória, ou seja, de transmissão, para uma herança quebequense, até então sem lugar de inscrição.

« Uma herança que não foi precedida de nenhum testamento », para retomar a frase de um contemporâneo do guarda-caça Martin, o poeta René Char, ele também integrante da resistência francesa contra a ocupação alemã ${ }^{9}$.

\section{BIBLIOGRAPHY}

Alburni, Robert, «La rage de l'expression » (critique du film Le Règne du jour), Cahiers du cinéma, $\mathrm{n}^{\circ}$ 208, janvier 1969, p. 60-61.

Bazin, André, «O cinema e a exploração », in André Bazin, O que é o cinema, São Paulo, Editora Cosacnaify, 2014, p. 47-56.

Certeau, Michel de, A invenção do cotidiano. I. Artes do fazer, Rio de Janeiro, Vozes, 2004.

Char, René, Fureur et mystère, Paris, Gallimard, 1967.

Didi-Huberman, Georges, Quand les images prennent position. L'oeil de l'histoire, Vol. I, Paris, Les Éditions de Minuit, 2009.

Garneau, Michèle, «Ce qui nous rattache au temps: le réveil du passé chez Pierre Perrault et Fernand Dumont ", in Michèle Garneau e Johanne Villeneuve (dir.), Traversées de Pierre Perrault, Québec, Éditions FIDES, 2009, p. 109-138.

Gervaiseau, Henri Arraes, $O$ abrigo do tempo. Abordagens cinematograficas da passagem do tempo, São Paulo, Alameda, 2012.

Marie, Michel, « Le direct et la parole », in Roger Odin e Jean-Charles Lyant (dir.), Cinémas et réalités, Saint-Etienne, Universidade de Saint-Etienne, 1984, p. 47-56.

Marsolais, Gilles, La trilogie de l'Isle-aux-Coudres, in Denys Desjardins (dir.), L'Oeuvre de Pierre Perrault, Volume I, La trilogie de l' ̂̂le aux Coudres. Textes et témoignages, Montréal,ONF, 2007, p. 9-20.

Filmografia

Lafond, Jean Daniel, Les traces du rêve (1986) 
Perrault, Pierre, Le règne du jour (1967)

Perrault, Pierre, Les voitures d'eau (1968),

Perrault, Pierre, Un pays sans bon sens (1970)

Perrault, Pierre, L'Acadie, l'Acadie ?! (1971)

Perrault, Pierre, La grande allure (1984)

Perrault, Pierre, C'était un québecois en Bretagne, madame (1977)

Perrault, Pierre, Les voiles en bas et en travers (1983)

Perrault, Pierre, La grande allure (1984)

\section{NOTES}

1. Em que mais do que tudo o que conta são as vicissitudes do percurso do viajante ocidental na travessia de países distantes (Bazin A., 2014 : 50).

2. Michel Serres diz que acredita que Pierre «tenta uma viagem no espaço, no tempo e no corpo social ». A fala do renomado filósofo francês está incluída em Les traces du rêve (1986), belíssimo filme de Jean Daniel Lafond sobre Pierre Perrault e a sua obra (a declaração está mais ou menos em 55min10s.).

3. Sobre Vertov e Flaherty, ver Gervaiseau (2012).

4. Pescado em Para a continuação do mundo.

5. Me apoio aqui em Didi-Huberman e na síntese que efetua do pensamento de Brecht a respeito do teatro épico, a partir das reflexões de Walter Benjamin (Didi-Huberman G., 2009: 60).

6. Segundo Michèle Garneau, que cita Paul Ricoeur, Le règne du Jour é o filme de Perrault que mais dá a ver essa memória transgeracional (Garneau M., 2009 : 117).

7. A referida sequência começa em 1h06mn3s, e o filme dura 1h58mn19s.

8. A fala de Garneau encontra-se em La Grande allure (1984), entre 13mn35s e 14mn15s.

9. A frase do René Char é: «A nossa herança não é precedida de nenhum testamento. No original francês : « Notre héritage n'est précédé d'aucun testament » (Char R., 1967 : 102).

\section{ABSTRACTS}

The organization of journeys with characters is a fruitful way to stimulate, in their minds, comparisons between one before and one after. The adoption of such an approach allows not only to reveal the becoming of characters, but also to favor the emergence of narratives related to the passages between before and after the journey. Besides, the crossing of social and geographic spaces distant of their daily experience can stimulate the exercise of comparison between ways of life and of being in the world. This affects directly the central issue of belonging of the characters in the movies of Quebec filmmaker Pierre Perrault. In this paper, we approach these questions through the discussion of Perrault's movie Le règne du jour (1967). 
A organização de viagens com os personagens é um frutífero modo de estimular, no espírito dos mesmos, comparações entre um antes e um depois do percurso. A adoção de uma tal abordagem permite não apenas evidenciar um devir, mas ainda favorecer a emergência de narrativas a respeito das passagens entre esse antes e esse depois. Além disso, a travessia de espaços sociais e geográficos distantes de suas vivências cotidianas estimula o exercício da comparação entre modos de vida e de estar no mundo, e toca diretamente, no caso dos personagens dos filmes do cineasta quebequense Pierre Perrault, na questão central do pertencimento. Neste artigo, abordamos essas questões a partir da discussão do filme Le règne du jour (1967).

L'organisation de voyages avec des personnages est une fructueuse manière de stimuler, dans leur esprit, des comparaisons entre un avant et un après. L'adoption d'une telle approche permet non seulement de donner à voir le devenir des personnages, mais encore de favoriser l'émergence de récits relatifs aux passages entre cet avant et cet après du parcours. En outre, la traversée d'espaces sociaux et géographiques distants de leur vécu quotidien est susceptible de stimuler l'exercice de la comparaison entre des modes de vie et d'être au monde, et touche directement, dans le cas des personnages des films du cinéaste québecois Pierre Perrault, la question centrale de l'appartenance. Dans cet article, nous abordons ces questions à partir de la discussion du film Le règne du jour (1967).

La organización de viajes con personajes es un fructífero modo de estimular, en el espíritu de los mismos, comparaciones entre un antes y un después. La adopción de tal abordaje permite no sólo evidenciar un devenir, sino también favorecer la emergencia de narrativas con respecto a los pasajes entre este antes y este después del viaje. Además, la travesía de espacios sociales y geográficos distantes de sus vivencias cotidianas estimula el ejercicio de la comparación entre modos de vida y modos de estar en el mundo, y toca, directamente, en el caso de los personajes de las películas del cineasta quebequense Pierre Perrault, la cuestión central de la pertenencia. En este artículo, abordaremos estas cuestiones a partir de la discusión de la película Le règne du jour (1967).

INDEX

Mots-clés: Perrault, documentaire, appartenance, voyage, passage

Palavras-chave: Perrault, documentário, pertencimento, viagem, personagem, narrativa, passagens

Palabras claves: Perrault, documental, pertenencia, viaje, pasaje

Keywords: Perrault, documentary film, belonging, journey, passage

\section{AUTHOR}

\section{HENRI ARRAES GERVAISEAU}

Cineasta, pesquisador e professor livre-docente do Departamento de Cinema, Televisão e Rádio da Escola de Comunicação e Artes da Universidade de São Paulo. Atualmente, o seu principal tema de investigação é o filme documentário como meio de expressão da experiência do deslocamento.

\section{CTR-ECA-USP}

Avenida Prof. Lúcio Martins Rodrigues, 443- Cidade Universitária.

CEP: 05508-900. São Paulo, SP, Brasil

henrigervaiseau@uol.com.br 